\title{
Bazalt tozu katkılı harçların mekanik ve geçirimlilik özeliklerinin araştırılması
}

\author{
Veysel AKYÜNCÜ*, Mehmet Timur CİHAN \\ Tekirdă̆ Namık Kemal Üniversitesi, Çorlu Mühendislik Fakültesi, İnşaat Mühendisliği Bölümü, \\ Çorlu Kampüsü, Tekirdăg. \\ Geliş Tarihi (Received Date): 19.12.2018 \\ Kabul Tarihi (Accepted Date): 18.03.2019
}

\section{Özet}

Bazalt beton üretiminde agrega olarak tercih edilen ancak üretimi esnasında yan ürün olarak yüksek miktarda atık bazalt tozu malzemesi ortaya çıkaran bir kayaçtır. Bu atık malzemenin geri dönüşümüyle çevreye ve insan să̆lı̆̆ına verdiği zararın azaltılmasının yanında çimentoyla ikame edilmesi harç (beton) hammadde maliyetinde bir miktar düşme sağlayacaktır. Çalışma kapsamında kontrol serisi ve \%5, \%10, \%15, \%20 oranlarında bazalt tozu çimento ile ikame edilerek toplamda 5 seri harç numune üretilerek taze ve sertleşmiş harç deneyleri gerçekleştirildi. Taze harç deneyi olarak kıvam tayini, sertleşmiş harç deneyi olarak basınç, eğilme, yarmada çekme ve geçirimlilik deneyi olarak basınç altında su işleme derinliği deneyleri yapıldı. \%10 ikameli seride basınç dayanımında yaklaşık olarak \%8 oranında artış elde edilirken, eğilme dayanımında ise \%15 ikameli seride önemli bir artış elde edildi. \%10 bazalt tozu ikame oranına sahip seride basınç altında su işleme derinliği düşüş göstererek olumlu bir katkı sağlamaktadır.

Anahtar kelimeler: Atık bazalt tozu, harç, basınç dayanımı, eğilme dayanımı, yarmada çekme dayanımı, permeabilite.

\section{Investigation of the mechanical and permeability properties of mortars containing basalt powder}

\begin{abstract}
Basalt can be used as aggregate in concrete however, very fine waste basalt powder is released as by-product during aggregate production. The hazardous effect of this waste material on human health and environment can be diminished while using basalt

\footnotetext{
*Veysel AKYÜNCÜ, vakyuncu@nku.edu.tr, http://orcid.org/0000-0003-3171-1553

Mehmet Timur CIHAN, mehmetcihan@nku.edu.tr, http://orcid.org/0000-0001-5555-5589
} 
powder as cement replacement material. In this study, reference and basalt powder added mortars were casted. Basalt powder was replaced at different percentages by weight of cement such as 5\%, 10\%, 15\% and 20\%. Workability (flow-table), compressive strength, flexural strength, splitting tensile strength and permeability tests were performed at fresh and hardened state of mortars. In the $10 \%$ incremental series, an increase of approximately $8 \%$ was obtained in the compressive strengths and a significant increase in the flexural strength in the 15\% substituted grades was obtained. A significant decrease was obtained at permeability of mortar with $10 \%$ basalt powder replacement as result of having denser structure at paste phase.

Keywords: Waste basalt powder, mortar, compressive strength, flexural strength, splitting tensile strength, permeability.

\section{Giriş}

Sürdürülebilir üretim günümüz koşullarında atık malzemelerin yeniden kullanımını zorunlu kılmaktadır. Oluşan atık ürünlerin bertarafı ekonomik açıdan üreticilerin sürdürülebilirliğini olumsuz etkilemektedir. Atık maddelerin farklı endüstrilerde yeniden geri kazanımı (hammadde olarak kullanılması), atık maddelerin doğurduğu problemlerin önüne geçmekle beraber ekonomiye fayda sağlamaktadır.

Agrega ve su dünyada en çok tüketilen hammaddelerdir [1]. \%58'lik oranla agrega üretimi maden sektörü içinde en yüksek orana sahiptir. Çevre kirliliği bakımından yapı malzemelerinin üretimi birtakım olumsuz etkilere neden olmaktadır. Agregaların üretimi esnasında ortaya çıkan tozlar insan sağlı̆̆ına ve çevreye önemli derecede zarar vermektedir. $\mathrm{Bu}$ nedenle agrega üretimi sırasında çıkan tozların harçta kullanılması çevre kirliliğini azaltmasının yanında ülke ekonomisine de katkı sağlayacaktır.

Mermer ve granit endüstrisi tarafından üretim esnasında çevreye, toprağa ve su kirliliğine neden olan büyük oranda atık toz meydana gelmektedir ve oluşan tozun farklı endüstrilerde hammadde olarak kullanılması konusunda çeşitli ülkelerde araştırmalar yapılmaktadır [2]. Mermer ve granit tozlarının çimento yerine alternatif bir malzeme ve dolgu malzemesi olarak kullanılabilirliği konusunda araştırmalar bulunmaktadır [2].

Harç TS EN 13055 (2016) standardına [3] göre, çimentonun silisli bir kumla karıştırılması ve bu karışıma su ilavesiyle elde edilen bir bağlayıcı malzeme olarak tarif edilmektedir. Nitelikli bir harç beton içerisinde agrega tanelerinin etrafını sarmalı, dayanım ve dayanıklılık özeliklerini servis ömrü boyunca yerine getirerek kendisinden beklenen performansı göstermelidir.

Beton; agrega, çimento hamuru ve bu iki bileşenin ara yüzeyinden oluşan üç fazlı heterojen bir malzemedir. Agrega çimento hamuru ara yüzeyi, betonda en zayıf halka olarak bilinmektedir ve bu bölge betonda çatlakların ilerlemesi açısından en uygun fazdır. Agrega-çimento hamuru ara yüzeylerinde çatlakların oluşması, betonun elastik olmayan davranışında önemli rol oynamaktadır. Mikro çatlakların iri agrega ve onu çevreleyen harçta başlaması ve çatlak ilerlemesinin ara yüzeyde gerçekleşmesi betonun bu fazının önemine işaret etmektedir. $\mathrm{Bu}$ nedenle harç özeliklerindeki iyileştirme betonun dayanım ve dayanıklılık özeliklerine çok önemli bir katkı yapmaktadır $[4,5]$. Betonun geçirimliliği boşlukların boyutuna ve dağılımına bağlıdır. Boşlukların boyutu 
ve dağılımı ise su/çimento oranı, çimento içeriği, çimento inceliği, çimento tipi, çimentoya ilave veya ikame olarak katılan mineraller, kimyasal katkılar, betonun yerleşmesi, ortam koşulları, kür koşulları gibi etkenlerden etkilenmektedir. Ayrıca hidratasyonun gelişimi ve çimentonun özelikleri de beton geçirimliliğini etkileyen diğer etkenlerdir $[6,7,8]$.

Agrega üretimi esnasında ortaya çıan atık toz malzemelerin beton üretiminde kullanılabilirliği ile ilgili çalışmalar yapılmaktadır [9, 10]. Dobiszewska ve diğ. (2018) [9] bazalt tozu atıklarının beton üretiminde kullanılması üzerine yaptıkları çalışmalarında ince agreganın atık bazalt tozu ile yer değiştirmesi halinde basınç ve eğilme dayanımında belirli bir artış meydana geldiğini beton kalitesine olumsuz bir etki yapmadığını, atık bazalt tozunun ince malzeme olarak değerlendirilebileceğini belirlemişlerdir. Böylece bazalt tozu atıklarının beton üretiminde ince malzeme olarak kullanılmasının ekonomiye katkısının yanında çevreye verdiği zararın da engellenmesine neden olacağ 1 belirtilmiştir.

Laibao ve diğ. (2013) [11] ise bazalt agregası üretiminde ortaya çıkan atık bazalt tozunun insan sağlı̆̆ına ve çevreye verdiği zararı belirtmiş, bazalt tozunun yeni bir mineral katkı olarak kullanılabilirliği konusunu incelemişlerdir. Çalışmada öncelikle bazalt tozunun kimyasal bileşimi ve puzolanik aktivitesi tespit edilmiş olup, çimento pastası ve atık bazalt tozu ile üretilen numunelerin basınç dayanımı belirlendikten sonra atık bazalt tozlu harçlarda izotermal kalorimetrik ölçüm, x 1şını difraksiyonu (XRD) ve taramalı elektron mikroskobu (SEM) testi ile hidratasyon süreci ve mikroyapısı incelenmiştir. Sonuç olarak bazalt tozunun belirgin bir puzolan faaliyet gösterdiği ve bir mineral katkı maddesi olarak kullanılabileceği tespit edilmiştir.

$\mathrm{Bu}$ çalışmada Tekirdağ bölgesinde yer alan bazalt ocaklarından agrega üretim aşamasında ortaya çıkan atık bazalt tozunun çimento ile yer değiştirilmesi ile üretilmiş harç numunelerinin geçirimlilik ve mekanik özelikleri karşılaştırmalı olarak incelendi. Elde edilen sonuçlar, bazalt tozunun harç üretiminde kullanım miktarının ve harç özeliklerinde oluşturacağı iyileştirme düzeyinin belirlenmesine olanak sağlamaktadır. Ayrıca harç fazının özeliklerinde gerçekleşecek iyileştirmelerin beton özeliklerine anlamlı etki yapacağı unutulmamalıdır.

\section{Deneysel çalışmalar}

\subsection{Malzeme}

Harç üretimi TSE EN 196-1'e [12] uygun CEM I 42.5 R çimento, CEN standard kum ve içilebilir su kullanılarak gerçekleştirilmiştir. Harç bileşim malzemelerine (çimento, bazalt tozu) ait özelikler Tablo 1'de görülmektedir. Harç üretiminde d50 değeri $30 \mu$ olan bazalt tozu, çimento ile ikameli olarak kullanılmıştır. CEN standard kuma ait agrega tane dağılımı Tablo 2'de görülmektedir. 
Tablo 1. Çimento ve bazalt tozunun özelikleri.

\begin{tabular}{|c|c|c|c|}
\hline \multicolumn{2}{|l|}{ Bileşim (\%) } & CEM I 42.5 R & Bazalt tozu \\
\hline \multicolumn{2}{|l|}{$\mathrm{CaO}$} & 62.85 & 12.38 \\
\hline \multicolumn{2}{|l|}{$\mathrm{SiO}_{2}$} & 19.52 & 44.25 \\
\hline \multicolumn{2}{|l|}{$\mathrm{Al}_{2} \mathrm{O}_{3}$} & 5.36 & 11.56 \\
\hline \multicolumn{2}{|l|}{$\mathrm{Fe}_{2} \mathrm{O}_{3}$} & 3.38 & 10.63 \\
\hline \multicolumn{2}{|l|}{$\mathrm{MgO}$} & 1.15 & 9.52 \\
\hline \multicolumn{2}{|l|}{$\mathrm{SO}_{3}$} & 3.36 & 0.45 \\
\hline \multicolumn{2}{|l|}{$\mathrm{Na}_{2} \mathrm{O} / \mathrm{K}_{2} \mathrm{O}$} & $0.22 / 0.72$ & $0.85 / 2.36$ \\
\hline \multicolumn{2}{|l|}{$\mathrm{Cl}^{-}$} & 0.0415 & 0.215 \\
\hline \multicolumn{2}{|l|}{$\mathrm{H}_{2} \mathrm{O}$} & - & 0.2 \\
\hline \multicolumn{2}{|l|}{ Kızdırma kaybı } & 3.29 & - \\
\hline \multicolumn{2}{|l|}{ Çözünmez kalıntı } & 0.24 & - \\
\hline \multicolumn{4}{|l|}{ Fiziksel özelikler } \\
\hline \multicolumn{2}{|l|}{ Özgül ağırlık } & 3.14 & - \\
\hline \multicolumn{2}{|c|}{ Özgül yüzey $\left(\mathrm{cm}^{2} / \mathrm{g}\right)$} & 3810 & - \\
\hline \multicolumn{2}{|c|}{ İncelik (90 $\mu$ Elek üzerinde kalan \%) } & 0.2 & 48.8 \\
\hline \multirow[t]{2}{*}{ Priz süresi (min) } & Başlangıç & 115 & - \\
\hline & Bitiş & 189 & - \\
\hline \multicolumn{2}{|c|}{ Hacim genleşmesi (mm) } & 1 & - \\
\hline \multicolumn{4}{|c|}{ Mekanik özelikler } \\
\hline \multirow[t]{3}{*}{ Dayanım (MPa) } & 2 günlük & 28,6 & - \\
\hline & 7 günlük & 41,3 & - \\
\hline & 28 günlük & 62,5 & - \\
\hline
\end{tabular}

Tablo 2. CEN standard kuma ait agrega tane dağılımı.

\begin{tabular}{|r|c|c|c|c|c|c|}
\hline Kare elek göz açıklığ $(\mathrm{mm})$ & 0.08 & 0.16 & 0.50 & 1.00 & 1.60 & 2.00 \\
\hline Elekten geçen kümülatif toplam (\%) & $99 \pm 1$ & $87 \pm 5$ & $67 \pm 5$ & $33 \pm 5$ & $7 \pm 5$ & 0 \\
\hline
\end{tabular}

Bazalt Tozunun Puzolanik Aktivitesi TS 25'e [13] göre belirlenmiş olup puzolanik aktivite deney sonuçları Tablo 3'te verilmiştir. TS 25'e [13] göre deney uygulandığında kireç - tras karışımı ile hazırlanan deneme numunelerinin 7 günlük eğilmede çekme dayanımı en az $10 \mathrm{kgf} / \mathrm{cm}^{2}$ ve 7 günlük basınç dayanımı en az $40 \mathrm{kgf} / \mathrm{cm}^{2}$ olmalıdır. Puzolanların dayanım sonuçları TS 25'te belirtilen sınır değerlerin üzerindedir. Bazalt tozunun TS 25 'e göre puzolanik aktiviteye sahip olduğu söylenebilir.

Tablo 3. Puzolanik aktivite deney sonuçları.

\begin{tabular}{|c|c|c|}
\hline \multirow{2}{*}{ Puzolan } & \multicolumn{2}{|c|}{ Mekanik Özelikler $\left(\mathrm{kgf} / \mathrm{cm}^{2}\right)$} \\
\cline { 2 - 3 } & Eğilme Dayanımı & Basınç Dayanımı \\
\hline Bazalt Tozu & 20 & 55 \\
\hline TS 25 sınırı & $\geq 10$ & $\geq 40$ \\
\hline
\end{tabular}

\subsection{Deneysel çalışma}

Deneysel çalışma, numune üretimi, kürü, fiziksel ve mekanik deneyler olmak üzere 3 aşamadan oluşmaktadır. Bir dizi deneme üretimi yapılarak s/ç oranı 0.6 olarak alınmıştır. Bazalt tozunun (çimento ile yer değiştirilmesi) harçların fiziksel (basınç altında su işleme derinliği) ve mekanik (basınç dayanımı, eğilme dayanımı ve yarmada 
çekme dayanımı) özeliklerine etkisinin belirlenmesi amacıyla 6 adet kontrol harç numunesi olmak üzere toplamda $18(6+12)$ adet 100·100·100 mm küp numunesi, 18 $(6+12)$ adet $40 \cdot 40 \cdot 160$ prizma numunesi üretildi. Harç üretiminde $\% 5, \% 10, \% 15$ ve $\% 20$ oranlarında çimento ile yer değiştirilerek bazalt tozu kullanıldı. Üretilen harç numunelerinin kodlanması ve karışım miktarları Tablo 4'de görülmektedir. Harç kıvamı TS EN 1015-3 (2000) "Kagir harc1- Deney metotları- Bölüm 3: Taze harç kıvamının tayini (yayılma tablası ile)" [14] standardına göre belirlendi. Basınç ve eğilme deneyleri, TS EN 196-1, (2009) "Çimento deney metotları - Bölüm 1: Dayanım tayini”" [12] deney standardına göre yapıldı.

Tablo 4. Harç numunelerinin kodlanması ve $1 \mathrm{~m}^{3}$ için gerekli karışım miktarları.

\begin{tabular}{|l|c|c|c|c|c|}
\hline $\begin{array}{c}\text { Numune } \\
\text { kodu }\end{array}$ & Çimento & $\begin{array}{c}\text { CEN standard } \\
\text { kum }\end{array}$ & $\mathrm{Su}$ & $\begin{array}{c}\text { Bazalt } \\
\text { tozu }\end{array}$ & $\begin{array}{c}\text { Bazalt tozu çimento yer } \\
\text { değiştirme oran1 }\end{array}$ \\
\cline { 2 - 6 } & $\mathrm{kg}$ & $\mathrm{kg}$ & $\mathrm{kg}$ & $\mathrm{kg}$ & çimentonun kütlece \% \\
\hline ÇBT\%0 & 496.0 & 1488 & 297.6 & 0.0 & 0 \\
\hline ÇBT\%5 & 471.2 & 1488 & 297.6 & 24.8 & 5 \\
\hline ÇBT\%10 & 446.4 & 1488 & 297.6 & 49.6 & 10 \\
\hline ÇBT\%15 & 421.6 & 1488 & 297.6 & 74.4 & 15 \\
\hline ÇBT\%20 & 396.8 & 1488 & 297.6 & 99.2 & 20 \\
\hline
\end{tabular}

Basınç altında su işleme derinliği tayini, TS EN 12390-8 (2010) [15] "Beton Sertleşmiş beton deneyleri - Bölüm 8: Basınç altında su işleme derinliğinin tayini standardına uygun olarak gerçekleştirildi. Basınç altında su işleme derinliğinin tayini deney düzeneği Şekil 1, eğilme ve yarmada çekme deney düzeneği ise Şekil 2'de görülmektedir.
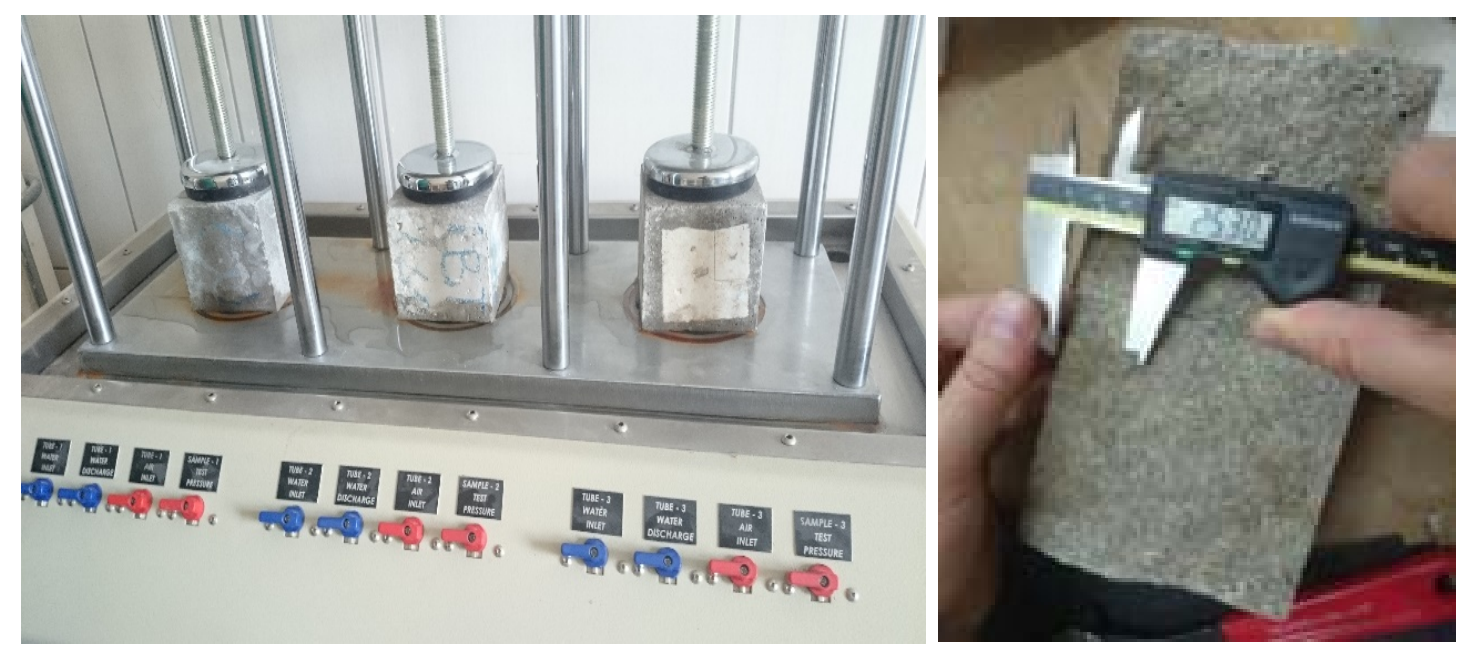

Şekil 1. Basınç altında su işleme derinliğinin tayini. 

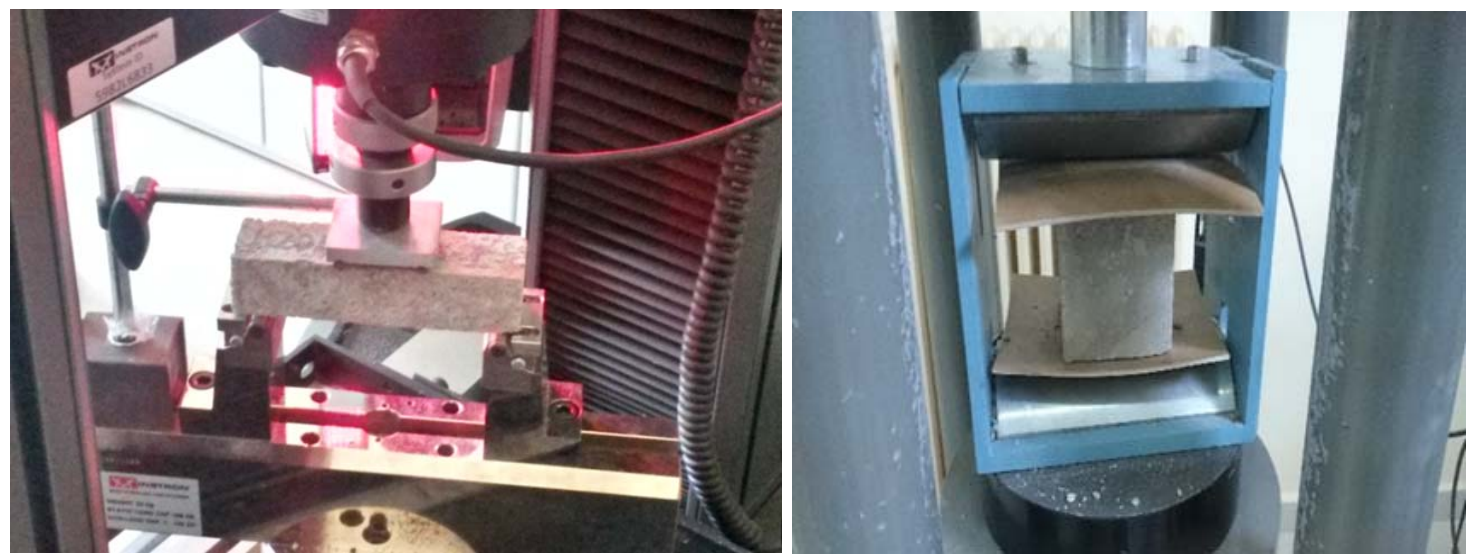

Şekil 2. Harç numunelerinde eğilme ve yarmada çekme deneyi.

\section{Sonuçlar ve tartışma}

Harç numuneleri üzerinde yayılma tablası, 28. gün sonunda gerçekleştirilen basınç dayanımı, eğilme dayanımı, yarmada çekme dayanımı ve basınç altında su işleme derinliğinin tayini deney sonuçları Tablo 5'de görülmektedir.

Tablo 5. Harç numunelerine ait ölçüm sonuçları.

\begin{tabular}{|c|c|c|c|c|c|}
\hline $\begin{array}{c}\text { Numune } \\
\text { kodu }\end{array}$ & $\begin{array}{c}\text { Yayılma } \\
(\mathrm{cm})\end{array}$ & $\begin{array}{c}\text { Basınç } \\
\text { Dayanımı } \\
(\mathrm{MPa})\end{array}$ & $\begin{array}{c}\text { Eğilme } \\
\text { Dayanımı } \\
(\mathrm{MPa})\end{array}$ & $\begin{array}{c}\text { Yarmada Çekme } \\
\text { Dayanımı (MPa) }\end{array}$ & $\begin{array}{c}\text { Basıç̧lı Su } \\
\text { İşleme Derinliği } \\
(\mathrm{mm})\end{array}$ \\
\hline ÇBT\%0 & 18.5 & 25.9 & 6.1 & 4.4 & 23.9 \\
\hline ÇBT\%5 & 18.0 & 27.4 & 6.4 & 4.4 & 24.0 \\
\hline ÇBT\%10 & 18.5 & 28.1 & 6.9 & 4.5 & 24.3 \\
\hline CBR\%15 & 17.5 & 26.9 & 7.1 & 4.4 & 25.2 \\
\hline ÇBT\%20 & 17.0 & 26.1 & 7.0 & 4.3 & 24.1 \\
\hline
\end{tabular}

Yayılma değerinin, çimento-bazalt tozu ikame oranına göre değişimi Şekil 3'de görülmektedir. Çimento- bazalt tozu ikame oranının \% 0 olduğu durum ile \%20 olduğu durum arasında $1.5 \mathrm{~cm}$ 'lik bir yayılma farkı bulunmaktadır. Yayılma değerleri genel olarak azalma eğiliminde olup, bunun nedeni ise bazalt agregasının özgül ağırlı̆̆ının çimentonun özgül ağırlığına göre daha düşük olmasından kaynaklanmaktadır. Bazalt tozu aynı ağırlığa sahip çimentoya göre daha fazla hacim kaplamaktadır. 


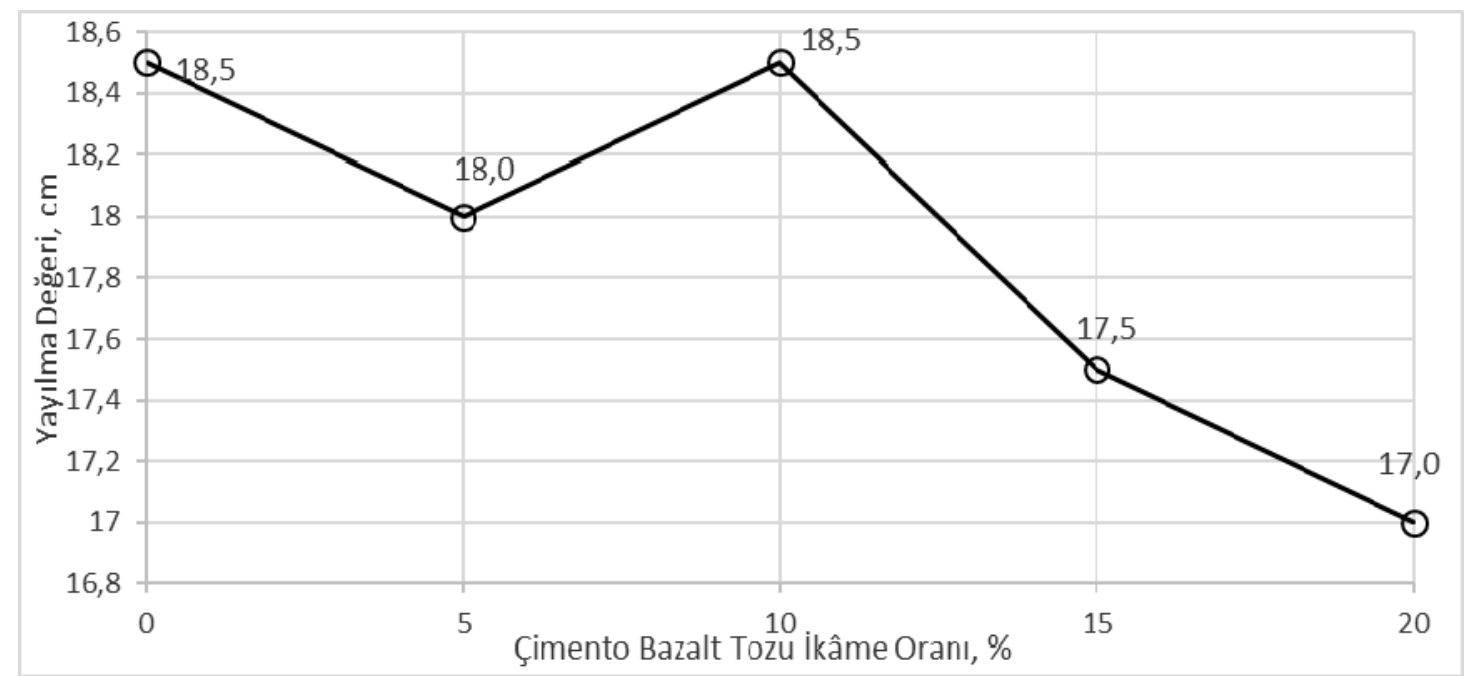

Şekil 3. Çimento bazalt tozu ikâme oranına göre yayılma değerinin değişimi.

Basınç dayanımının, çimento-bazalt tozu ikame oranına göre değişimi Şekil 4'de görülmektedir. Basınç dayanımında, çimento bazalt tozu ikame oranının \%0 olduğu durum ile $\% 20$ olduğu durum arasında $0.4 \mathrm{MPa}$ 'lık bir fark olduğu görülmektedir. $\% 0$ ve \%20 çimento bazalt tozu ikame oranları arasında basınç dayanımı grafiğinde, artışlar ve düşüşler görülmektedir. \% 5'lik çimento-bazalt tozu ikame oranında $1.5 \mathrm{MPa}$ 'lık bir artış söz konusu iken, bu durum \%10'luk ikame oranında $2.2 \mathrm{MPa}$ 'lık bir artış meydana getirmiştir. En yüksek basınç dayanımı, çimento bazalt tozu ikame oranının \%10 olduğu durumda gözlenmektedir. Deney sonuçlarına göre, atık bazalt tozu ikameli harçların agrega-çimento hamuru ara yüzeyi boşluk yapısı üzerinde olumlu etki yaptığı ayrıca Duan ve arkadaşları[16] tarafından yapılan çalışmayla benzerlik gösterdiği söylenebilir. Mineral katkı kullanımıyla birlikte daha dolu ve yoğun bir yapı meydana gelmiş özellikle agrega-çimento hamuru ara yüzeyi güçlenmiştir.

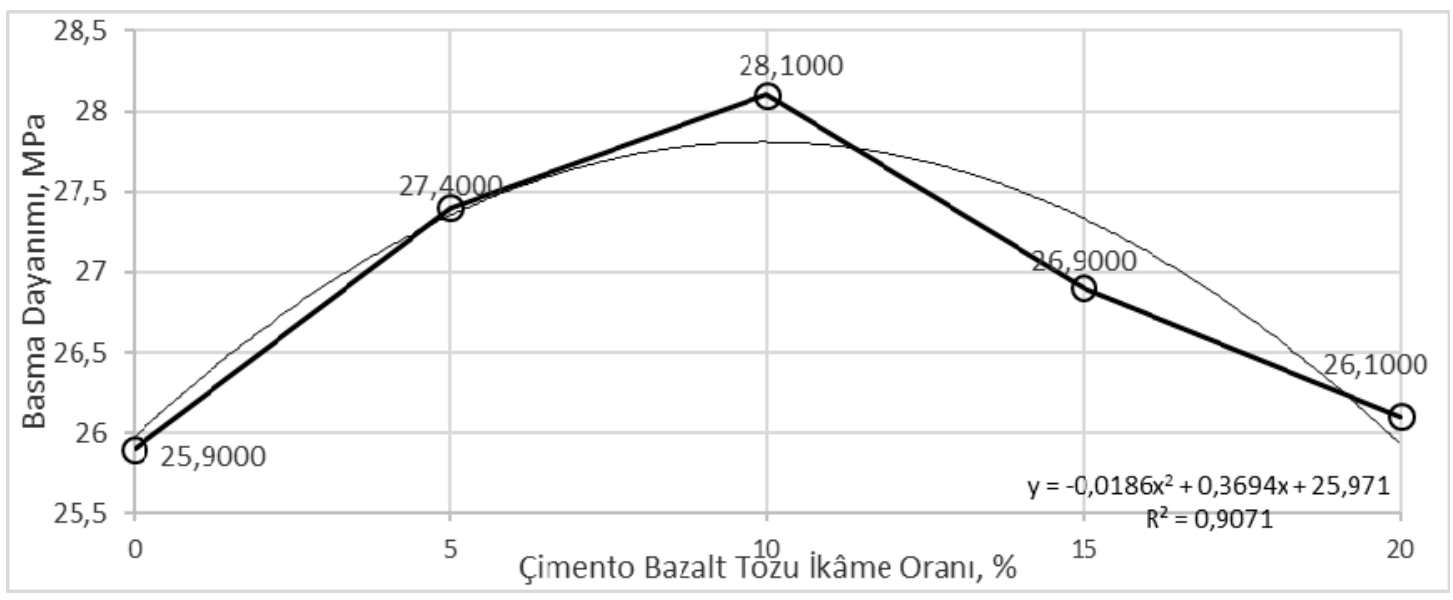

Şekil 4. Çimento bazalt tozu ikâme oranına göre basınç dayanımının değişimi.

Eğilme dayanımının, çimento-bazalt tozu ikame oranına göre değişimi Şekil 5'te görülmektedir. Çimento bazalt tozu ikame oranındaki artış ile eğilme dayanımında yükselme görülmektedir. Çimento bazalt tozu ikame oranının $\% 0$ olduğu durum ile $\% 15$ olduğu durum arasında yaklaşık olarak $0.9 \mathrm{MPa}$ dayanım farkı bulunmaktadır. Maksimum harç eğilme dayanımı, çimento bazalt tozu ikame oranının \%15 olduğu durumda görülmektedir. Kullanılan mineral katkının incelik derecesine bağlı olarak 
puzolanik reaksiyon hızında da artış meydana gelmektedir. Puzolanik aktiviteye bağlı olarak oluşan ürünler çimento hamurunun yoğunluğunu arttırarak çimento taneleri arasındaki boşluklarda da azalma sağlamıştır [17, 18].

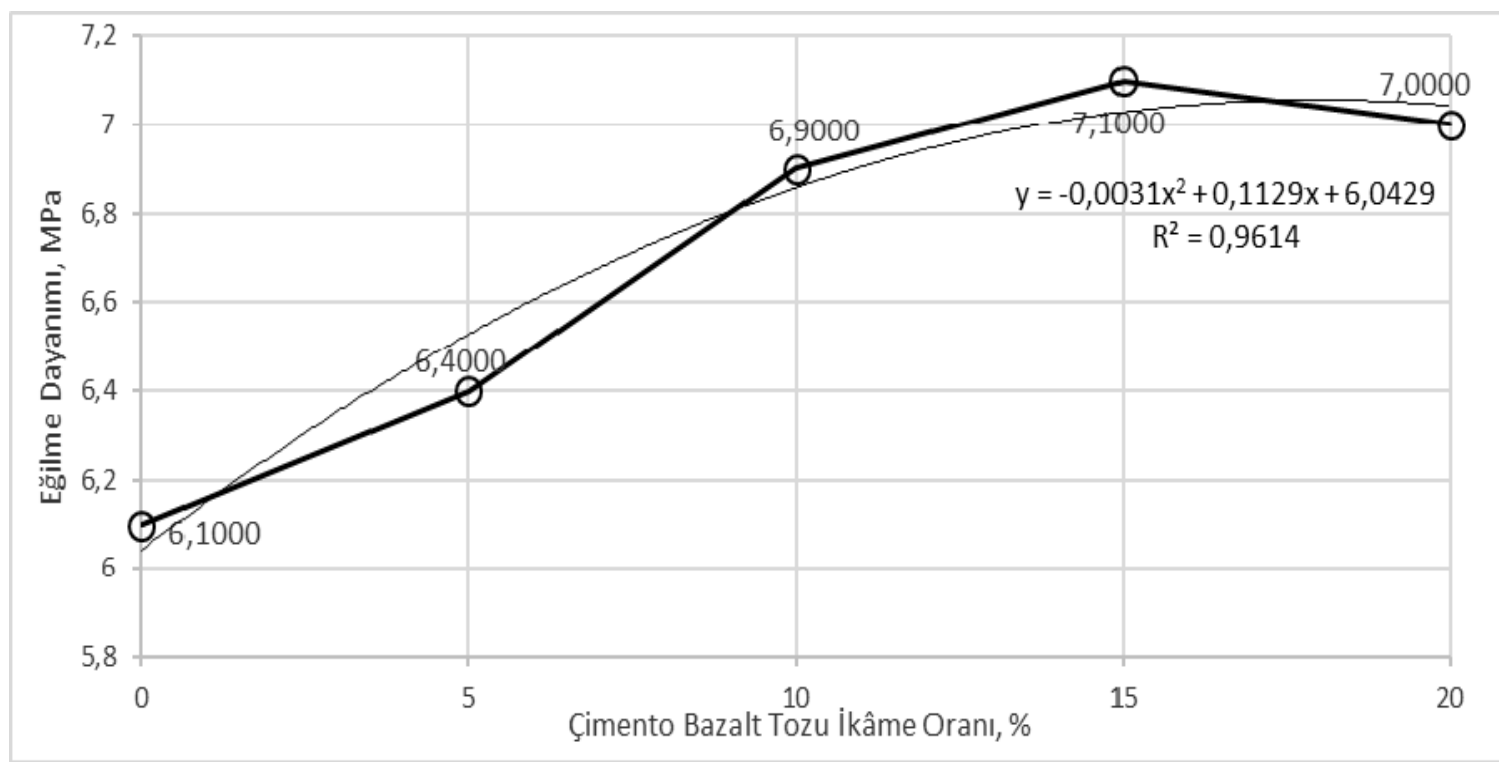

Şekil 5. Çimento bazalt tozu ikame oranına göre eğilme dayanımının değişimi.

Yarmada çekme dayanımının, çimento-bazalt tozu ikame oranına göre değişimi Şekil 6'da görülmektedir.

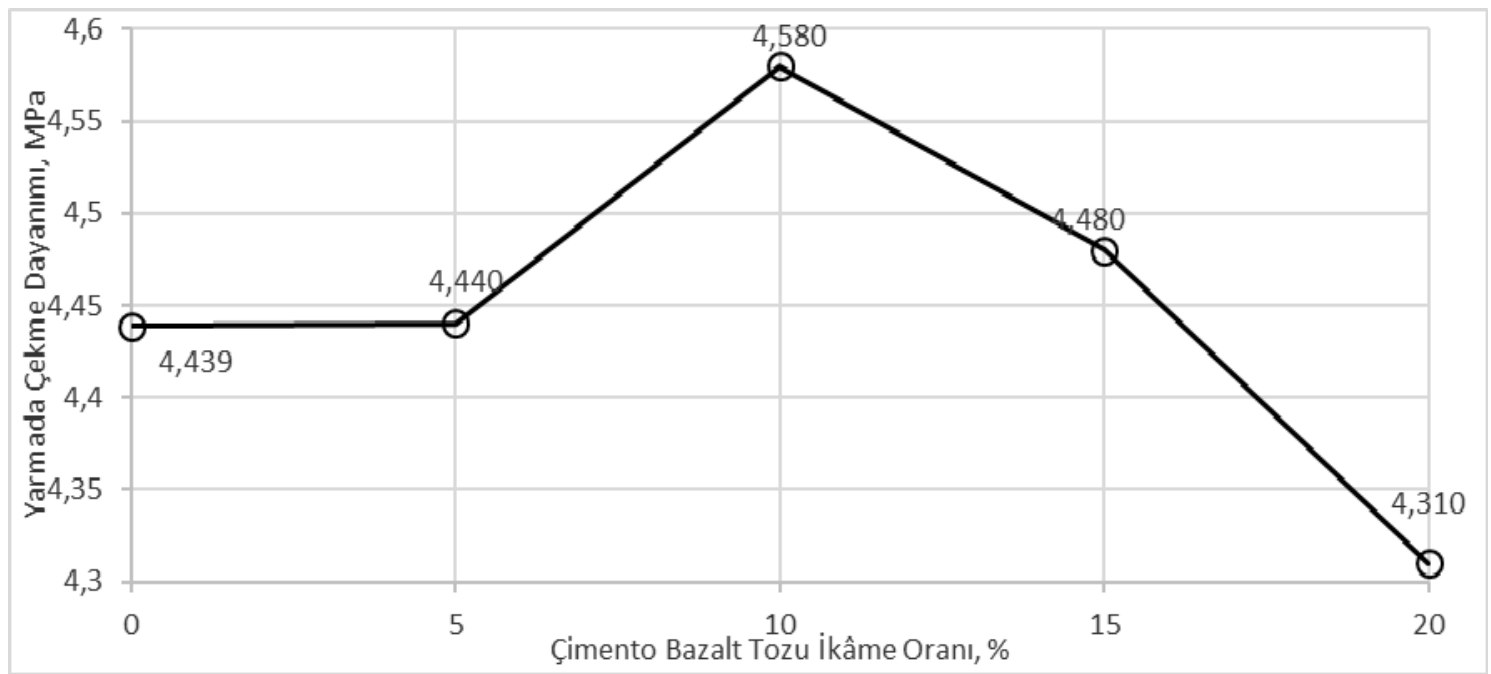

Şekil 6. Çimento bazalt tozu ikame oranına göre yarmada çekme dayanımının değişimi.

Yarmada çekme dayanımında, çimento bazalt tozunun $\% 0$ olduğu durum ile $\% 20$ olduğu durum arasında yaklaşık olarak $0.75 \mathrm{MPa}$ 'lı bir dayanım farkı olduğu görülmektedir. Yarmada çekme dayanımındaki değişkenlik, çimento bazalt tozu ikame oranındaki artışa bağlı olarak \%10 seviyesinde 0.141 MPa'lık bir artış sağlamıştır.\%10\%20 arasında yarmada çekme dayanımında düşüş meydana gelmiştir.

Basınç altında su işleme derinliğinin, çimento bazalt tozu ikame oranına göre değişimi Şekil 7'de görülmektedir 


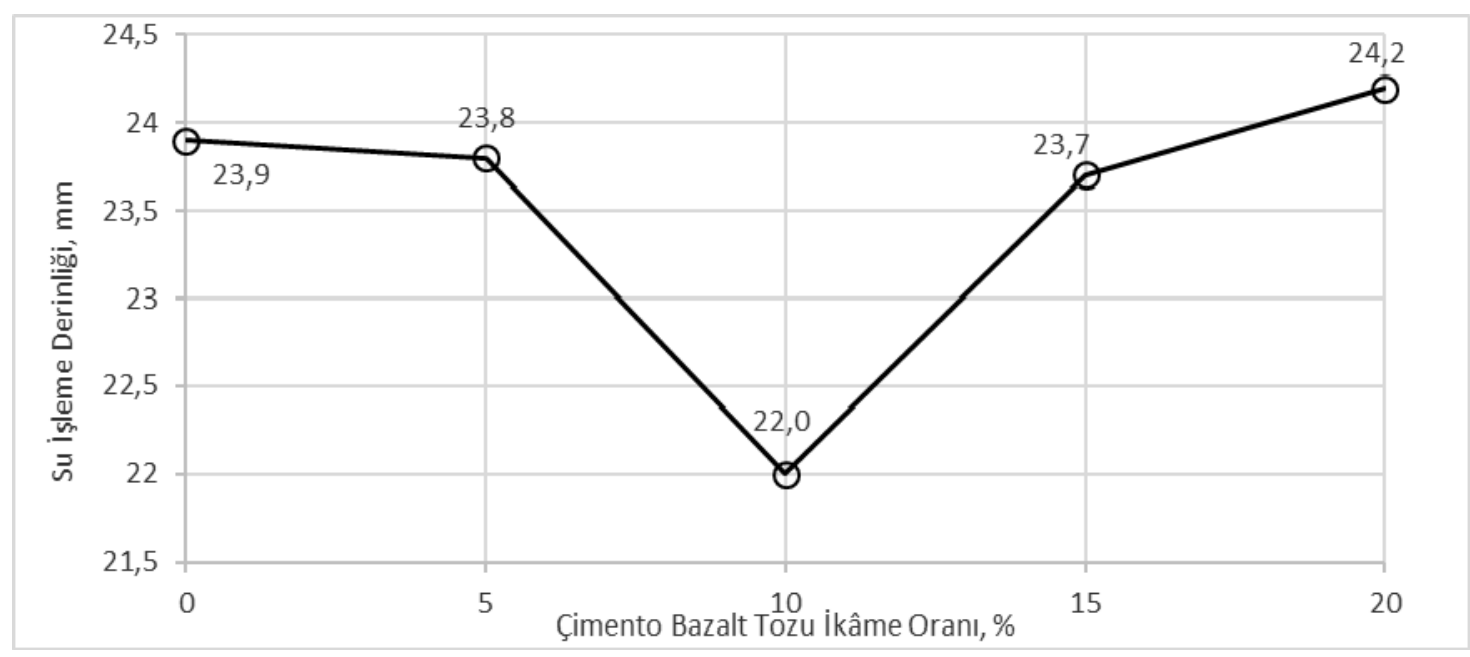

Şekil 7. Çimento bazalt tozu ikame oranına göre su işleme derinliğinin değişimi.

Basınç altında su işleme derinliğinde, çimento-bazalt tozu ikame oranının $\% 0$ ve $\% 5$ olduğu durumlar arasında belirgin bir fark göze çarpmamaktadır. \%10 ikame oranında 1.9 mm'lik bir düşüş meydana gelmiştir. Çimento-bazalt tozu ikame oranının, \%10'dan $\% 15$ 'e arttırılmasıyla, grafikte ani bir yükselme gerçekleşmekte ve basınç altında su işleme derinliği kontrol serisine yakın bir değer almaktadır. \%20 ikame oranında 24.2 mm olmak üzere en yüksek değere ulaşmaktadır. Çimento harcı boşluk yapısındaki kapiler boşluklarda mineral katkı kullanımı ile önemli derecede azalmalar ve jel boşluklarında ise artışlar müşahede edilmiştir [19, 20].

Basınç, eğilme, yarmada çekme dayanımları ve su işleme derinliğinin çimento bazalt tozu ikame oranına göre değişimi Şekil 8'de görülmektedir.

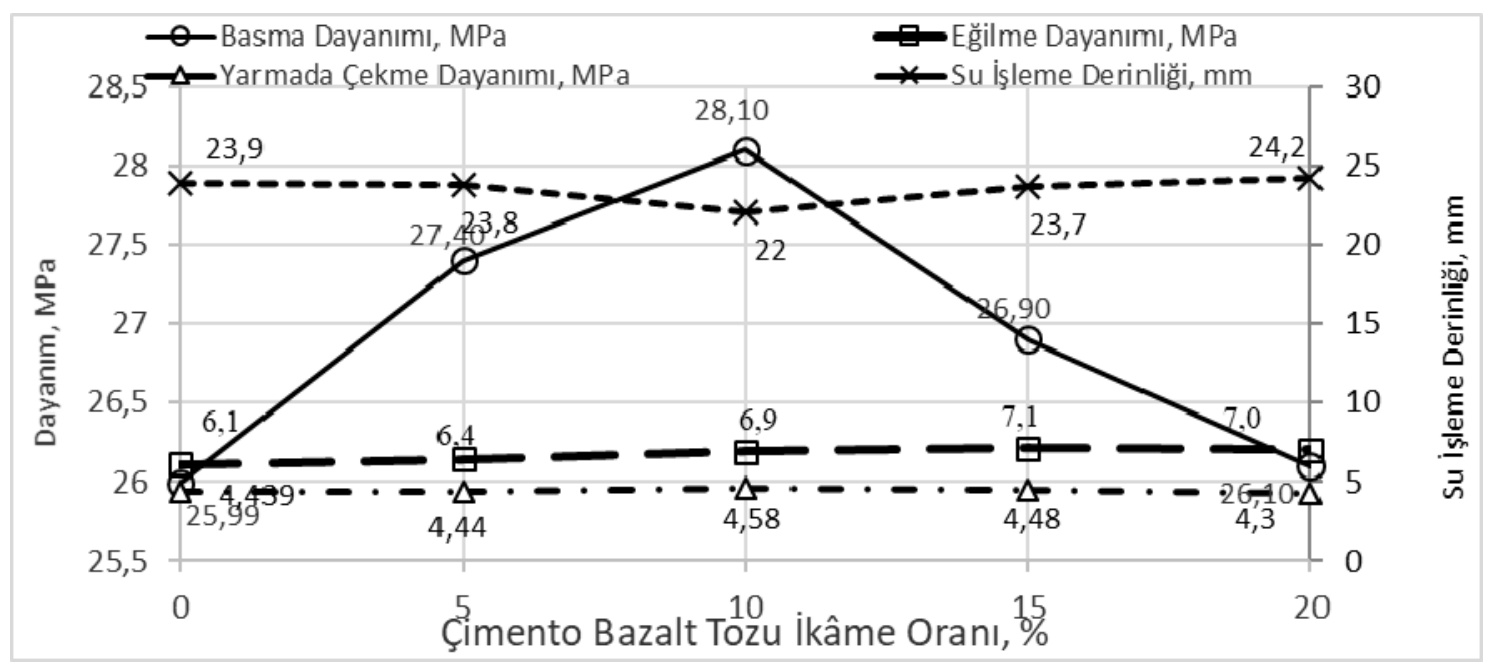

Şekil 8. Çimento bazalt tozu ikame oranına göre basınç, eğilme, yarmada çekme dayanımı ve su işleme derinliğinin değişimi.

Şekil 8 incelendiğinde yarmada çekme dayanımı ve eğilme dayanımlarının çimento bazalt tozu ikame oranına göre benzer davranış gösterdiği görülmektedir. Basınçlı su işleme derinliğindeki değişim çok düşük $(1.9 \mathrm{~mm})$ olmaktadır. Basınç dayanımı \%10 ikame değerinde yaklaşık \% 7.5 oranında artış göstermiştir. $\mathrm{Bu}$ nedenle çimento ile 
bazalt tozunun yer değiştirilerek üretilen numunelerde bazalt tozunun filler etkisi oluşturmadığı söylenebilir.

Deneysel sonuçlardan elde edilen verilerin değerlendirilmesi aşağıda sıralanmıştır:

- Yapılan basınç deneyinde, kontrol numunesi ile çimento bazalt tozu ikame oranının \%10 olduğu numuneler arasında $2.2 \mathrm{MPa} l 1 \mathrm{k}$ dayanım farkı olduğu görülmektedir. Basınç dayanımı açısından çimento bazalt tozu ikame oranı \%10 olarak harç numunelerinde kullanılması tercih edilebilir. Çimento bazalt tozu ikamesi ile basınç dayanımında meydana gelen yükselmenin nedeni mineral katkı içeren harçların içinde portland çimentosu ile yapılmış harçlara oranla daha az serbest kireç ve daha çok kalsiyum silikat hidrat bileşikleri bulunmasıdır.

- Çimento bazalt tozu ikame oranındaki artış ile eğilme dayanımında yükselme görülmektedir. Eğilme dayanımı açısından çimento bazalt tozu ikame oranı \%15 kullanılması tercih edilebilir. Ekonomik nedenlerle çimento bazalt tozu ikame oran $\% 15$ yerine $\% 20$ miktarında da kullanılabilir.

- Yarmada çekme deneyi sonucunda, çimento bazalt tozu ikame oranının \%10 olması durumunda yarmada çekme dayanımında \%3'lük bir artış görülmektedir. Fakat $\% 20$ oranında \%3 kadar bir azalma olduğu görülmektedir; dolayısıyla yarmada çekme dayanımı açısından $\% 5$ ve $\% 15$ arasında bazalt tozunun mineral katkı olarak kullanılması bir değişikliğe neden olmamaktadır.

- Su işleme derinliğinde, çimento-bazalt tozu ikame oranının $\% 0$ ve $\% 5$ olduğu durumlar arasında belirgin bir fark göze çarpmamaktadır. \%10 ikame oranında 1.9 mm'lik bir azalma ile $22 \mathrm{~mm}$ olmak üzere en düşük değer ölçülmüştür. Çimento-bazalt tozu ikame oranının, \%10'dan \%20'e arttırılmasıyla, grafikte bir yükselme gerçekleşmekte ve $24.2 \mathrm{~mm}$ olmak üzere en yüksek değere ulaşmaktadır. Geçirimsizlik açısından çimento bazalt tozu ikame oranının \%10 olarak kullanılması tercih edilmelidir. Geçirimliliğin azalmasının nedeni bazalt tozunun mineral katk1 olması yanında ince bir dolgu maddesi olmasından kaynaklanmaktadır. Ayrıca puzolanik etki sonucu serbest kireci bağlayarak çimento hamuru boşluk yapısında oluşan değişimler nedeniyle geçirimlilik azalmaktadir.

- Puzolanlardaki $\mathrm{CaO} / \mathrm{SiO}_{2}$ oranı arttıkça C-S-H azalmaktadır. $\mathrm{CaO} / \mathrm{SiO}_{2}$ oran kontrol numunelerde 3.22 iken bazalt tozu ikamelilerde 0.28 mertebesindedir. $\mathrm{Bu}$ nedenle bazalt tozu ikameli karışımlarda C-S-H oranı yüksek olduğundan atık bazalt tozu mekanik özeliklere olumlu katkı sağlamaktadır.

- Bazalt tozunun çimento ile \%10 yer değiştirilerek kullanılması harç numunelerinin mekanik ve fiziksek özeliklerini iyileştirmektedir. Fakat harç numunelerinin dayanıklılık özelikleri üzerindeki etki düzeyinin de belirlenerek ortaya konmasi gerekmektedir.

\section{Kaynaklar}

[1] Öztürk, Ö., Çelikkol M. ve Erkan M., Türkiye Agrega Sektör Raporu, Agrega Üreticileri Birliği, İstanbul, (2007). 
[2] Bacarji, E., Toledo Filho, R. D., Koenders, E.A.B., Figueiredo, E.P. and Lopes, J.L.M.P., Sustainability perspective of marble and granite residues as concrete fillers, Construction and Building Materials, 45, 1-10, (2013).

[3] TS EN 13055, Hafif agregalar - Bölüm 1: Beton, harç ve şerbette kullanım için, Türk Standartları Enstitüsü, Ankara, (2016).

[4] Baradan, B., Yazıcı, H. ve Aydın S., Beton, DEÜ Mühendislik Yayınları, (2012).

[5] Neville A.M. and Brooks J.J., Concrete Technology, Pearson, Prentice Hall, 257-262, (2001).

[6] Neville, A. M., Properties of Concrete, Longman, 433-434, (1995).

[7] Mehta, P.K., Pore Size Distribution and Permeability of Hardened Cement Pastes, 7th Int. Cong. on the Chemistry of Cement, Paris, 3 (7), 1-5, (1980).

[8] Ertün, T., Türker, P. ve Başkoca, A., Farklı çimento tipleriyle hazırlanan yüksek performanslı harçların geçirimliliği, 6. Ulusal Beton Kongresi, 361-369, (2005).

[9] Dobiszewska, M., Schindler, A.K., Pichór, W., Mechanical properties and interfacial transition zone microstructure of concrete with waste basalt powder addition, Construction and Building Materials, 177, 222-229, (2018).

[10] Saraya, M.E.I., Study physico-chemical properties of blended cements containing fixed amount of silica fume, blast furnace slag, basalt and limestone, a comparative study, Construction and Building Materials, 72, 104-112, (2014).

[11] Laibao, L., Yunsheng, Z., Wenhua, Z., Zhiyong, L. and Lihua, Z., Investigating the influence of basalt as mineral admixture on hydration and microstructure formation mechanism of cement, Construction and Building Materials, 48, 434-440, (2013).

[12] TS EN 196-1, Çimento deney metotları - Bölüm 1: Dayanım tayini, Türk Standartları Enstitüsü, Ankara, (2009).

[13] TS 25, Doğal puzolan (tras) - Çimento ve betonda kullanılan - Tarifler, gerekler ve uygunluk kriterleri, Türk Standartları Enstitüsü, Ankara, (2008).

[14] TS EN 1015-3, Kagir harc1- Deney metotları- Bölüm 3: Taze harç kıvamının tayini (yayılma tablası ile), Türk Standartları Enstitüsü, Ankara, (2000).

[15] TS EN 12390-8, Beton - Sertleşmiş beton deneyleri - Bölüm 8: Basınç altında su işleme derinliğinin tayini, Türk Standartları Enstitüsü, Ankara, (2010).

[16] Duan, P., Shui, Z., Chen, W., and Shen, C., Effects of metakaolin, silica fume and slag on pore structure, interfacial transition zone and compressive strength of concrete, Construction and Building Materials, 44, 1-6, (2013).

[17] Mindess, S., Young, J.F., and Darwin, D., Concrete, second ed., Prentice-Hall, Upper Saddle River, NJ., (2003).

[18] Maekawa, K., Chaube, R., and Kishi, T., Modeling of concrete performance: hydration, microstructure formation and mass transport, Taylor \& Francis Group, London, (1999).

[19] Jiang, G., Rong, Z., and Sun, W., Effects of metakaolin on mechanical properties, pore structure and hydration heat of mortars at $0.17 \mathrm{w} / \mathrm{b}$ ratio, Construction and Building Materials, 93, 564-572, (2015).

[20] Kuzielová, E., Žemlička, M., Bartoničková, E., ve Palou, M.T., The correlation between porosity and mechanical properties of multicomponent systems consisting of Portland cement-slag-silica fume-metakaolin, Construction and Building Materials, 135, 306-314, (2017). 